\title{
DISPLASIAS CORTICALES COMO CAUSA DE EPILEPSIAY SUS REPRESENTACIONES EN LAS IMÁGENES
}

\author{
Dr. Marcelo Gálvez $M^{(1)}$, Ing Gonzalo Rojas C. ${ }^{(1)}$, Drs. Jorge Cordovez M..(1), David Ladrón de Guevara(1), \\ Manuel Campos $\boldsymbol{P}^{(2)}$, Isabel López $\boldsymbol{S}^{(3)}$. \\ 1. Departamento de Imágenes, Clínica Las Condes, Santiago. \\ 2. Departamento de Neurocirugía, Clínica Las Condes, Santiago. \\ 3. Departamento de Pediatría. Centro Avanzado de Epilepsias. Clínica Las Condes. Santiago. \\ e-mail:mgalvez@med.uchile.cl
}

\begin{abstract}
Epilepsy is a chronic neurological disorder characterized by spontaneous recurrent seizures, which are clinically classified as generalized or partial. Approximately, $30 \%$ of patients with partial epilepsy is refractory to medical treatment. Within the refractory group we must discard the presence of cortical dysplasia as an underlying cause of the crisis.

Cortical dysplasias are a type of malformations of cortical development (mcd) that are increasingly recognized as a cause of refractory epilepsy. From the radiological point of view this kind of pathology is of particular interest since imaging manifestations can be subtle or may show completely normal examinations.

The aim of this paper is to review the literature, describing the imaging appearance of the normal cortical development, the classifications of cortical malformations, mainly cortical dysplasias, by highlighting the most frequent radiological signs. We also examine the current role of positron emission tomography (pet) in epilepsy, which in conjunction with magnetic resonance imaging findings and electrophysiological studies are used to define a possible surgical treatment. Through this treatment we expect to be provided with details of histopathological alterations found in the surgical specimen to be compared to the radiographic changes revealed in the pre-surgical study.

Keywords: Brain pet, Epilepsy surgery, Focal cortical dysplasia, Magnetic resonante imaging (MRI), Malformation of cortical development (MCD), Mild malformation of cortical development, Refractory epilepsy.
\end{abstract}

\section{RESUMEN}

La epilepsia es una alteración neurológica crónica caracterizada por crisis convulsivas recurrentes y espontáneas, que clínicamente se clasifican como generalizadas o parciales, dentro de las cuales aproximadamente el $30 \%$ de los pacientes con epilepsia parcial son refractarios al tratamiento médico. Dentro del grupo refractario debemos descartar la presencia de una displasia cortical como causa subyacente de las crisis.

Las displasias corticales son un tipo de malformaciones del desarrollo cortical que en forma cada vez más frecuente se reconocen como causante de epilepsia refractaria. Desde el punto de vista radiológico, este tipo de patología tiene especial interés debido a que las manifestaciones imaginológicas pueden ser sutiles o presentar exámenes completamente normales.

El objetivo de este artículo es realizar una revisión de la literatura, describiendo el 
desarrollo cortical normal con su aspecto en imágenes, las clasificaciones de las malformaciones corticales y en especial de las displasias corticales, destacando los signos radiológicos más frecuentes. Además revisaremos el rol en la actualidad de la Tomografía por Emisión de Positrones (PET) en epilepsia, que en conjunto con las imágenes por resonancia magnética y los estudios electrofisiológicos se utilizan para definir un eventual tratamiento quirúrgico, el que una vez realizado nos da detalles del análisis de las alteraciones histopatológicas en la pieza quirúrgica versus las alteraciones radiológicas visualizadas en el estudio pre-quirúrgico.

Palabras clave: Cirugía de la epilepsia, Epilepsia refractaria, Displasia cortical focal, Malformación del desarrollo cortical, Malformación leve del desarrollo cortical, PET cerebral, Resonancia magnética.

\section{INTRODUCCIÓN}

La epilepsia es una alteración neurológica crónica, caracterizada por crisis convulsivas recurrentes y espontáneas, producidas por descargas eléctricas anormales de las neuronas corticales. Las descargas se producen debido a un aumento de la excitabilidad, o una depresión de los mecanismos inhibidores de la neurotransmisión.

Desde el punto de vista clínico, las epilepsias se clasifican como parciales, cuando las convulsiones se originan desde un área localizada del cerebro o generalizadas, cuando las convulsiones se originan simultáneamente de ambos hemisferios cerebrales.

Se estima una prevalencia del $1,7 \%$ en la población chilena, por lo que en el año 2009 existen aproximadamente 280.000 pacientes con epilepsia ${ }^{(1)}$. Se estima que un $30 \%$ de los pacientes con epilepsia parcial son resistentes a los fármacos antiepilépticos ${ }^{(2)}$, por lo que muchas veces la resección quirúrgica del foco epilptógeno es el único tratamiento efectivo.

Desde el punto de vista radiológico, el principal propósito de las neuroimágenes en los pacientes con epilepsia es identificar una alteración estructural que tenga relación con el tipo de crisis, localizar el foco eléctrico y proponer un diagnóstico etiológico.

En los casos de pacientes con epilepsia refractaria se ha descrito que las imágenes de resonancia magnética (RM) y tomografía computada (TC) sólo identifican una alteración subyacente entre el 82 y el $86 \%$ de los $\operatorname{casos}^{(3)}$. Otros estudios incluso han reportado que un $25 \%$ de los pacientes con epilepsia refractaria tienen $\mathrm{RM}$ normal( ${ }^{(4)}$.

Desde el punto de vista quirúrgico, las imágenes cumplen un rol fundamental en la localización anatómica de la lesión y su relación con las áreas elocuentes del cerebro (zonas que cumplen funciones especiales, como las áreas motoras, del lenguaje y de la visión).

Las principales causas de epilepsia demostrables por imágenes, en niños y adultos, corresponden a la esclerosis temporal mesial (esclerosis hipocampal), malformaciones del desarrollo cortical y tumores cerebrales.

Las displasias corticales corresponden a un tipo especial de alteraciones del desarrollo de la corteza cerebral que han sido reportadas, cada vez con más frecuencia, como causa subyacente de las crisis parciales refractarias. Tienen especial importancia para el radiólogo, debido a que muchas veces las alteraciones imaginológicas son sutiles o presentar exámenes completamente normales.

\section{DESARROLLO CORTICAL NORMAL Y SU ASPECTO EN LAS IMAGENES}

La corteza cerebral tiene una estructura altamente organizada y se encuentra ampliamente conectada con el resto de las estructuras encefálicas y la médula espinal. Su formación es compleja y ocurre en etapas temporal y espacialmente ordenadas, incluso con la formación de estructuras transitorias que finalmente desaparecen.

Se han identificado tres principales etapas consecutivas del desarrollo de la corteza cerebral, cada una parcialmente sobrepuesta con la siguiente, conocidas como etapa de proliferación y diferenciación celular, etapa de migración neuronal y etapa de organización cortical ${ }^{(5,6,7)}$.

La etapa de proliferación y diferenciación neuronal ocurre a nivel periventricular en el interior de la matriz germinal, entre la $5^{\underline{a}}$ y $20^{\underline{a}}$ semana de gestación. Las células germinales se multiplican y se diferencian tanto en neuronas como en células gliales.

La etapa de migración ocurre entre la $6^{\underline{a}}$ y $22^{a}$ semanas de gestación. En esta etapa, las neuronas se adhieren a una fibra glial radial y cambian de posición desde la región periventricular hasta su posición final en la corteza cerebral.

La corteza cerebral normal contiene numerosas células, localizadas en sitios específicos que le otorgan una arquitectura característica; se organiza en 6 capas que se enumeran desde la capa I, o molecular, hasta la capa VI o capa multiforme, sin embargo el proceso de migración se produce desde las capas más profundas hasta las capas más superficiales.

La etapa de organización cortical, que depende en parte del proceso de migración, ocurre entre las $22^{a}$ semana de gestación hasta los 2 años de vida. Las neuronas se diferencian en distintos subtipos celulares como células piramidales, células estrelladas, células multipolares y otras, que se organizan en láminas horizontales, conformando un patrón cito-arquitectónico cortical normal.

El desarrollo normal de cada una de las etapas le otorga a la corteza cerebral una apariencia histológica e imaginológica normal.

Histológicamente, la capa I (molecular) no tiene neuronas. La células piramidales se localizan en 
las capas III (piramidal externa) y capa V (piramidal interna); se caracterizan por su tamaño y orientación perpendicular a la superficie cortical. Las células piramidales normales de mayor tamaño se localizan en la capa $\mathrm{V}$.

En la corteza cerebral normal no existen neuronas inmaduras, así como tampoco áreas de gliosis que corresponden a zonas de reparación ante una noxa inespecífica sobre parénquima cerebral, caracterizada por proliferación de las células astrocitarias.

Normalmente existen muy pocas neuronas en la sustancia blanca. A nivel periventricular, la matriz germinal generalmente desaparece a las 32 semanas de gestación.

Imaginológicamente la corteza cerebral madura tiene una intensidad de señal uniforme, similar a los ganglios basales y presenta un espesor entre 2 a 5 $\mathrm{mm}$ de espesor, con un límite bien definido entre la corteza y la sustancia blanca.

La sustancia blanca tiene baja señal en las imágenes ponderadas en T2 en los mayores de 18 meses, principalmente determinada por el contenido lipídico de la mielina. Normalmente no existen focos sugerentes de gliosis en su espesor.

\section{MALFORMACIONES DEL DESARROLLO CORTICAL (MDC)}

Las malformaciones del desarrollo cortical (MDC) son un grupo heterogéneo de patologías caracterizadas por una corteza cerebral estructuralmente anormal, producto de una interrupción de la secuencia normal del desarrollo cortical, debido a causas internas como la falta de expresión genética normal, expresión genética anormal o causas externas como las infecciones prenatales, isquemia o exposición a tóxicos, que se manifiestan en algún tipo de MDC.

Las tres etapas del desarrollo cortical normal no se encuentran temporalmente separadas, la proliferación continúa luego que la migración comienza y la migración continúa después que se ha realizado. Hay que destacar que la célula que resulta de una proliferación anormal, frecuentemente no migra ni se organiza adecuadamente.

a. Alteraciones de la proliferación:

Las alteraciones de la proliferación se manifiestan por una disminución de la proliferación (microlisencefalia), por un aumento de la proliferación celular (hemimegalencefalia) o por una proliferación anormal (displasia cortical focal tipo II).

b. Alteraciones de migración:

Las alteraciones de la migración pueden producir una disminución de la migración (lisencefalia), una detención precoz de la migración con neuronas mal posicionadas a nivel periventricular o en la sustancia blanca (heterotopía periventricular o en banda), o en una sobremigración (distrofia muscular congénita). c. Alteraciones de la organización:

Las alteraciones de la organización producen trastornos de la estructura de la corteza como la polimicrogiria, esquizencefalia o displasias corticales focales tipo I.

Imaginológicamente, las alteraciones producidas durante la fase de proliferación se pueden extender desde los ventrículos hasta la superficie pial, mientras que las alteraciones de la fase de migración se localizan en la sustancia blanca y/o corteza. En general, las alteraciones de la organización se encuentran limitadas a la corteza cerebral( ${ }^{(8)}$.

\section{DISPLASIA CORTICALES FOCALES (DCFS)}

Las displasias corticales corresponden a un grupo heterogéneo de MDC, secundarias a una lesión durante los períodos de proliferación u organización cortical. Aunque su etiología no se encuentra completamente dilucidada, estas lesiones se caracterizan por la presencia de neuronas y células gliales anormales en una región de la corteza cerebral ${ }^{(9)}$.

La primera descripción de "displasias focales" fue realizada por Taylor ${ }^{(10)}$ en 1971, en pacientes con epilepsia fármaco resistente, para describir anormalidades focales de la estructura de la corteza cerebral caracterizadas por alteración de laminación, neuronas dismórficas y células en balón.

Los mecanismos fisiopatológicos por cuales las DCFs generan epilepsias no son claros $^{(11)}$, sin embargo el tejido displásico tendría una epileptogenicidad intrínseca ${ }^{(12)}$.

Los pacientes con DCF pueden presentar déficit neurológico focal, retraso del desarrollo psicomotor o crisis epilépticas; de hecho las displasias corticales se reconocen como la principal causa de epilepsia refractaria en niños y la segunda causa de crisis en adultos sometidos a cirugía de epilepsia.

Se estima que un $76 \%$ de los pacientes con DCFs sufren de epilepsia refractaria ${ }^{(13)}$, mientras que en un $25 \%$ de los pacientes con crisis epilépticas parciales se ha identificado una DCF como la causa subyacente ${ }^{(14)}$.

Histológicamente, las alteraciones descritas en las displasias corticales abarcan desde alteraciones mínimas como la presencia de neuronas en la primera capa de la corteza cerebral hasta alteraciones severas de la organización cortical con presencia de neuronas ectópicas, células anormales y gliosis.

Debido al avance logrado en los equipos de RM y software de post-proceso, las displasias corticales han comenzado a ser visibles en los pacientes estudiados por epilepsia.

Durante los últimos años se ha tratado de encontrar parámetros que permitan una correlación entre la clínica, los hallazgos electroencefalográficos, las alteraciones radiológicas y los hallazgos patológicos. Debido a esto, se han propuesto numerosas clasifica- 
ciones basadas tanto en alteraciones histopatológicas, como clínicas, embriológicas y genéticas.

Con el fin de llegar a un consenso, un panel de epileptólogos y neuropatológos, liderados por Palmini ${ }^{(15)}$ proponen una clasificación que considera diferentes subtipos histológicos que se correlacionarían con las manifestaciones clínicas y algunas alteraciones imaginológicas.

Se han descrito además algunas alteraciones menores de la organización de la corteza cerebral, que no alcanzan a clasificar como displasias corticales propiamente tales y que se han agrupado bajo el término "microdisgenesia". Estas se caracterizan por heterotopías microscópicas de las neuronas, sin células anormales ni alteración de la laminación. El panel propone cambiar el término "microdisgenesia" por el de "malformaciones leves del desarrollo cortical (MLDC)" para englobar este grupo de patologías. Sin embargo, hay que reconocer que todavía no existe un consenso unánime entre los expertos de la exacta definición de este grupo de patologías.

Las alteraciones histopatológicas encontradas en los pacientes con MLDC y DCFs abarcan: presencia de neuronas normales mal posicionadas, presencia de neuronas inmaduras o neuronas anormales con desorganización de las capas corticales (dislaminación) y presencia de gliosis reparativa ${ }^{(16)}$. Hay que destacar que algunos autores han demostrado que las alteraciones histopatológicas son un factor pronóstico, independiente para la cirugía.

El término dislaminación corresponde a la pérdida de la arquitectura cortical laminar por desorganización de las láminas normales y una transición borrosa entre las diferentes capas corticales. Se observa además un aumento homogéneo de la densidad celular.

El término displasia arquitectural corresponde a una laminación cortical alterada sin mayores alteraciones citológicas.

Las MLDC y las DFCs pueden presentar las siguientes alteraciones celulares:

a. Células normales heterotópicas:

En los casos más leves del espectro de las displasias corticales podemos encontrar neuronas mal posicionadas dentro de la corteza cerebral pero por fuera de la capa cortical que le corresponde, o neuronas heterotópicas a nivel de la sustancia blanca, como único hallazgo histopatológico.

b. Neuronas gigantes:

Células de morfología piramidal, anormalmente grandes, generalmente de mayor tamaño que las neuronas piramidales de la capa $\mathrm{V}$, pero localizadas fuera de ésta (Figura 1a).

c. Células inmaduras o indiferenciadas:

Corresponden a células pequeñas, redondas $u$ ovales, con un núcleo grande y halo citoplasmástico fino que se hallan dispersas o agrupadas en el espesor de la corteza cerebral. Estas células no se encuentran en la corteza cerebral de adultos normales y han sido identificadas como neuronas inmaduras (Figura 1b).

d. Neuronas dismórficas:

Corresponden a neuronas de morfología piramidal bizarra y tamaño anormal. Su orientación en el espesor de la corteza cerebral se encuentra alterada, ya que no siguen el eje perpendicular a la superficie cortical (Figura 1c).

e. Células balonadas:

Las células balonadas corresponden a células grandes, redondeadas, de citoplasma claro y con una membrana celular mal definida. Presentan uno o más núcleos excéntricos y muestran características inmunológicas tanto de neuronas como de células gliales, por lo que son células en un estado muy inmaduro de diferenciación (Figura 1d). Estas células se encuentran frecuentemente agrupadas a nivel de la unión de la SG-SB. No es claro el papel exacto que juegan las células balonadas en la epileptogénesis de las displasias corticales.

f. Proliferación astroglial:

Los pacientes con epilepsia tienen un grado variable de gliosis localizada en la sustancia blanca. La presencia de gliosis en el espesor del tejido displásico puede explicar la alteración de la señal en las imágenes ponderadas en T2 o FLAIR. La extensión de los cambios glióticos parece no relacionarse con la alteración de la laminación o la presencia de las células anormales.
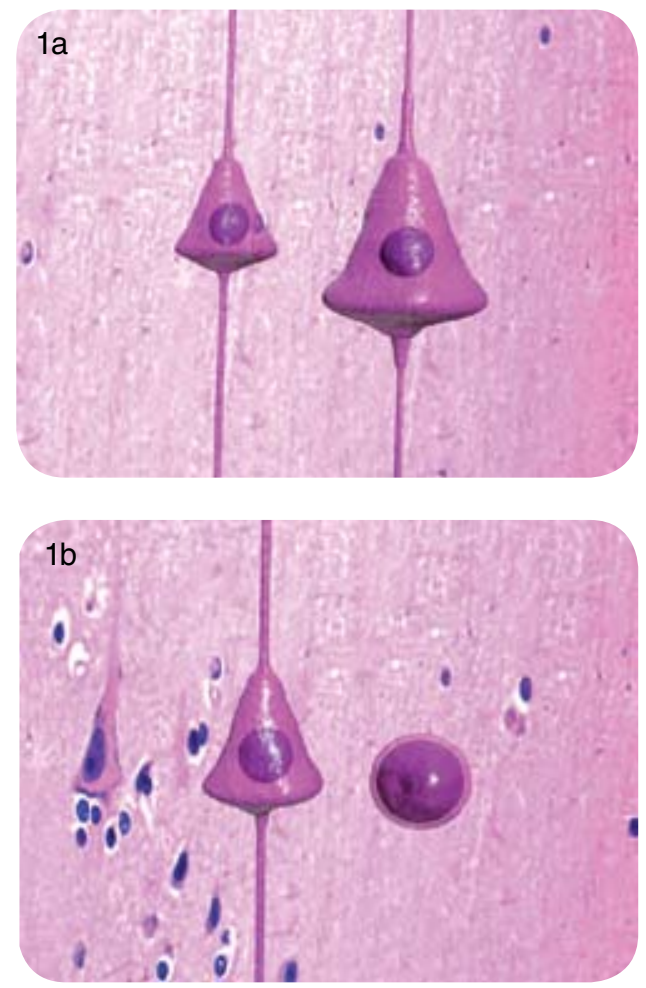

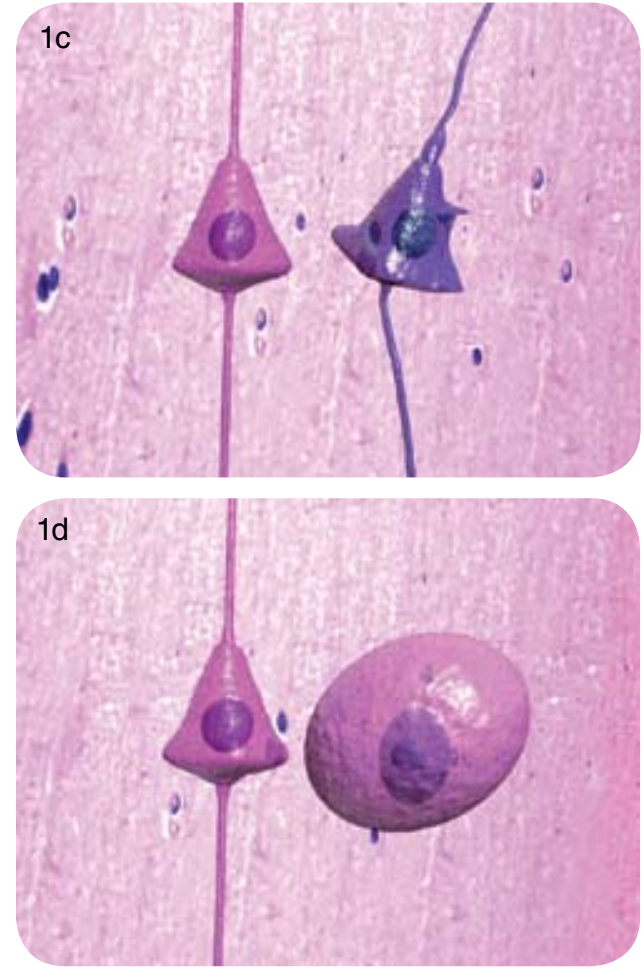

Figura 1. Tipos de células anormales encontradas en los pacientes con displasia cortical y su comparación con una neurona piramidal (capa V) normal. 1a: célula piramidal gigante. 1b: célula inmadura. 1c: célula dismórfica. 1d: célula balonada.

Dentro del espectro de esta patología debemos considerar los siguientes subgrupos:

\section{A. Malformación leve del desarrollo cortical (MLDC):}

El término "microdisgenesia" fue acuñado por Meencke en 1984, para describir una malformación microscópica que incluye neuronas heterotópicas en la capa I, que normalmente sólo contiene algunas células, y aumento del número de neuronas en la sustancia blanca ${ }^{(17)}$. Sin embargo, este término se utilizó también para nombrar un sinnúmero de alteraciones histológicas mal definidas e incluso para describir las lesiones que no eran visibles en la RM.

Debido a esto es que Palmini et $\mathrm{al}^{(15)}$ proponen abandonar el término "microdisgenesia" por el de "malformación leve del desarrollo cortical" para describir lesiones corticales focales caracterizadas por "microheterotopias" de neuronas normales, sin alteración de la arquitectura cortical. Se definen dos subtipos:

- MLDC Tipo I, que presentan neuronas ectópicas localizadas en la capa I o adyacentes a ella (Figura 2b), y

- MLDC Tipo II con heterotopías microscópicas fuera de la capa I (Figura 2c).

Además de su asociación con epilepsia, se han relacionado con alteraciones cognitivas y trastornos del comportamiento.
Hay que destacar que estas microheterotopías en la sustancia blanca han sido descritas en autopsias de pacientes normales, por lo cual la presencia de algunas neuronas en esta posición puede ser un hallazgo normal, especialmente en los lóbulos temporales ${ }^{(18)}$. Debido a esto, el hallazgo anormal posiblemente corresponda a un aumento de la densidad de neuronas, más que a la presencia de ellas.

Se ha propuesto que las MLDC no son detectables por RM, sin embargo se han demostrado alteraciones sutiles en las imágenes de pacientes con resección del foco epileptógeno.

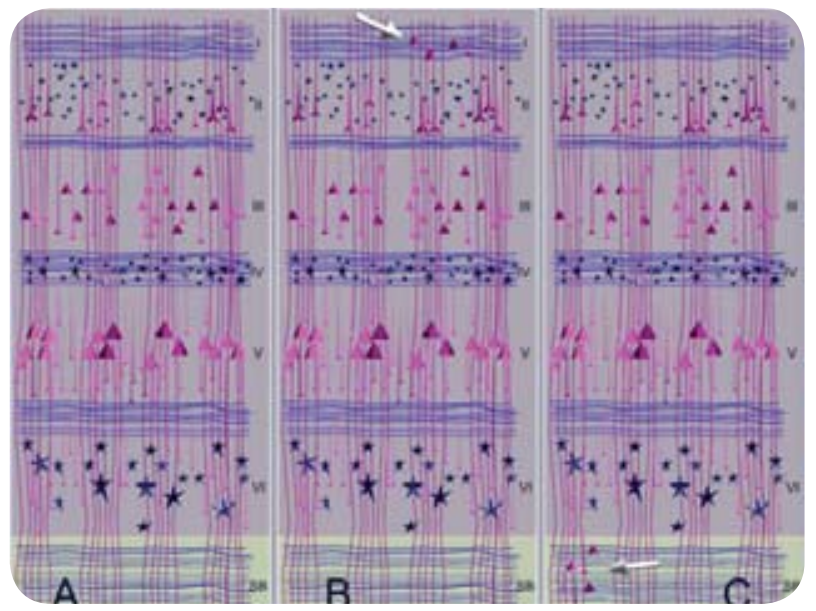

Figura 2. Malformaciones leve del desarrollo cortical (MLDC) comparadas con la corteza cerebral normal (2A). Presencia de células piramidales normales ectópicas (microheterotopias) con el resto de la estructura cortical normal y ausencia de células anormales. MLDC tipo I (2B) con un grupo de neuronas localizas en la capa I (flecha blanca). MLDC tipo II (2C) con neuronas localizas en la SB subcortical (flecha blanca).

\section{B. Displasia cortical focal (DCF) tipo I:}

Las DCF tipo I se clasifican en dos grupos: DCF Tipo IA que presenta alteraciones aisladas de arquitectura aisladas (Figura 3b) y DCF tipo IB que corresponden a la alteración de la arquitectura y la presencia de células gigantes o inmaduras, pero sin presencia de células dismórficas (Figura 3c).

Clínicamente los pacientes pueden desarrollar epilepsia, alteraciones del aprendizaje $u$ otros trastornos cognitivos. Sin embargo, las DCF tipo I pueden ser también clínicamente silentes. Un estudio demuestra la presencia de una DCF tipo I en cerca del $1,7 \%$ de los cerebros sanos ${ }^{(19)}$. Imaginológicamente presentan alteraciones leves o en algunas oportunidades pueden ser totalmente invisibles en las imágenes de RM.

Se localizan más frecuentemente a nivel temporal en pacientes adultos y frecuentemente con RM negativas. 


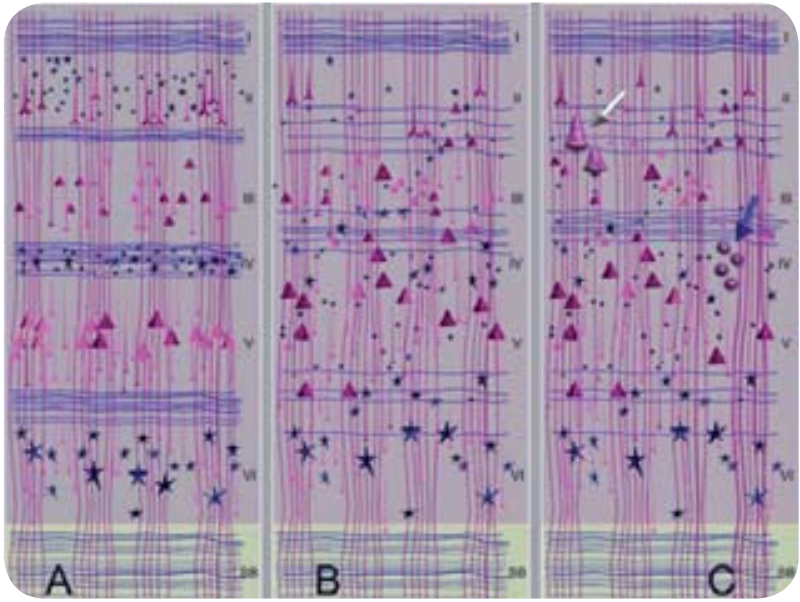

Figura 3. Displasia cortical focal (DCF) tipo I comparada con la corteza cerebral normal (3A). DCF tipo IA (3B) caracterizada por alteración de la arquitectura cortical, pérdida de la laminación cortical con neuronas piramidales normales fuera de las capas III y V. DCF tipo IB (3C) con alteración de la arquitectura más la presencia de células gigantes (flecha blanca) o inmaduras (flecha azul), pero sin la presencia de células dismórficas.

\section{Displasia cortical tipo II o de Taylor:}

Las DCF tipo II se caracterizan por la presencia de células verdaderamente anormales, groseramente dismórficas y que producen inhibición o excitación de la neurotransmisión por lo que tienen un alto grado de epileptogenicidad intrínseca.

Las áreas con características de DCF tipo II se consideran más epileptógenas que las de DCF tipo I(20).

Los pacientes con DCF tipo II se presentan a menor edad con mayor frecuencia de crisis que los pacientes con DCF tipo I, de hecho, se han asociado más a la presencia de epilepsia refractaria.

Su etiología se debería a una alteración de la diferenciación, tanto de las neuronas como las células gliales, asociada a un trastorno de los eventos migratorios posteriores ${ }^{(21)}$.

Histológicamente se caracterizan por alteración de la citoarquitectura normal de la corteza, causada por células bizarras grandes y desorientadas. Se observa además un aumento del número de células que se distribuyen anormalmente.

Se han descrito dos subtipos de DCF tipo II o tipo Taylor, las DCF tipo II A que presentan anormalidad de la arquitectura y neuronas dismórficas pero sin células balonadas (Figura 4 b), y las tipo II B que presentan además células balonadas (Figura 4c).

Se ha demostrado que el área con células balonadas es menos epileptógena que las áreas displásicas adyacentes.

Imaginológicamente estas lesiones se identifican como lesiones focales en la RM y pueden presentarse como un engrosamiento cortical focal, borrosidad de la unión de la sustancia gris y la sustancia blanca, aumento de la señal de la corteza en imágenes potenciadas en T2 o FLAIR y señal anormal de la sustancia blanca que se extiende desde la corteza a la superficie ventricular (displasia trans-manto).

Se localizan frecuentemente en situación extratemporal. Son relativamente bien definidas por lo que son susceptibles de ser corregidas quirúrgicamente.

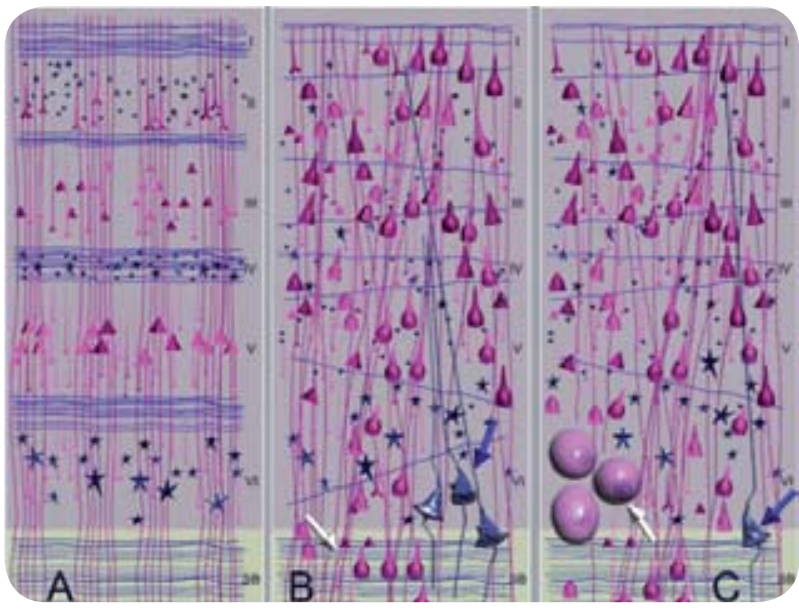

Figura 4. Displasia cortical focal (DCF) tipo II comparada con la corteza cerebral normal (4A). DCF tipo IIA (4B) caracterizada por alteración franca de la arquitectura cortical, con células piramidales gigantes y neuronas en la SB. Presencia de células dismórficas sin células balonadas. DCF tipo IIB (4C) similar al cuadro anterior pero con células balonadas generalmente ubicadas en la unión de la SG-SB.

\section{Patología dual:}

La patología dual corresponde a la presencia de una displasia cortical focal temporal asociada a esclerosis hipocampal. No es clara la relación entre las dos patologías y si una de ellas produce la otra.

Genéricamente, las displasias corticales leves corresponden al grupo de las MLDC y las DCF tipo I, mientras que las displasias severas corresponden a las DCF tipo II.

\section{MANIFESTACIONES IMAGINOLÓGICAS DE LAS DISPLASIAS CORTICALES}

\section{RESONANCIA MAGNÉTICA}

Los avances en las neuroimágenes han permitido un aumento de la detección de las DCF, revelando que este tipo de lesiones son más frecuentes de lo se creía previamente. De esta forma, ciertas epilepsias que se consideraban criptogénicas ahora se han asociado a displasias corticales ${ }^{(22)}$.

Sin embargo, tenemos pacientes en los cuales las imágenes de RM fallan en la detección de este tipo de lesiones. Se estima que aproximadamente un $25 \%$ de los pacientes con epilepsia refractaria tienen RM normal. Incluso se ha descrito que entre 
un 20 a un $50 \%$ de las DCFs sólo se reconocen en los estudios neuropatológicos ${ }^{(14)}$. Tassi describe que un $35 \%$ de los pacientes con displasias corticales confirmadas por histología tenían RM normales, sin grandes diferencias de sensibilidad en los casos de displasias corticales leves y severas ${ }^{(23)}$. Por lo tanto, se hace muy importante conocer la semiología de las crisis y las alteraciones eléctricas para buscar dirigidamente estas alteraciones.

Las alteraciones radiológicas descritas en los pacientes con DCF se localizan a nivel de la corteza, en la unión de la corteza con la sustancia blanca o en la sustancia blanca, principalmente a nivel subcortical; sin embargo estas alteraciones pueden extenderse incluso hasta contactar el sistema ventricular. Estas lesiones no tienen efecto de masa significativo y no se impregnan luego de la administración de contraste intravenoso.

Aunque diferentes hallazgos imaginológicos han sido asociados con DCF tipo I o II, existe una importante sobreposición entre los signos radiológicos y el tipo histopatológico, por lo que una categorización no puede ser hecha solamente en base a los hallazgos de la RM.

Los signos descritos son:

a. Engrosamiento cortical.

Corresponde a un área localizada de aumento del espesor de la corteza cerebral que puede ser desde una alteración sutil hasta un engrosamiento evidente, generalmente sin alteración de la intensidad de señal. Ha sido descrito en todos los tipos de DCF.

Se estima que en aproximadamente el $15 \%$ de los pacientes con displasia cortical leve el engrosamiento cortical sería la única manifestación radiológica (Figura 5).

En los casos de DCF II generalmente se asocia la presencia de borrosidad de la unión de la SG-SB y aumento de la señal subcortical, describiéndose esta asociación hasta en el $60 \%$ de los pacientes, siendo rara en los pacientes con displasias corticales leves ${ }^{(23)}$.

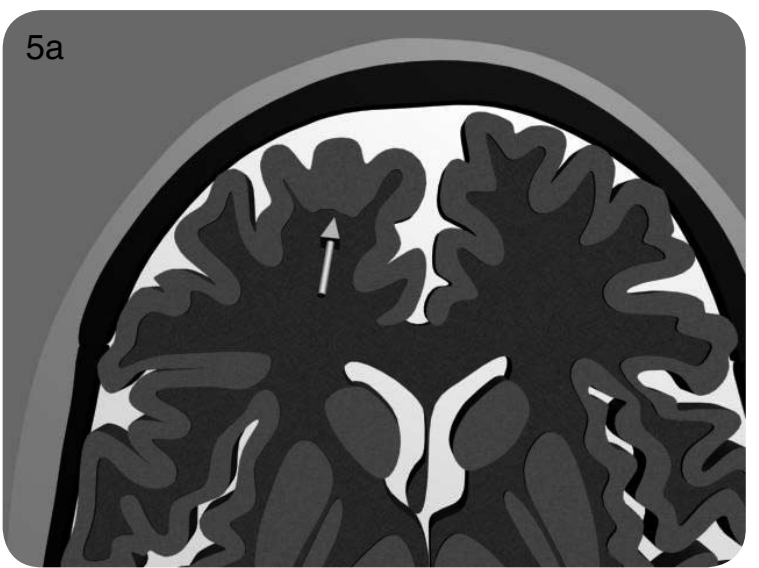

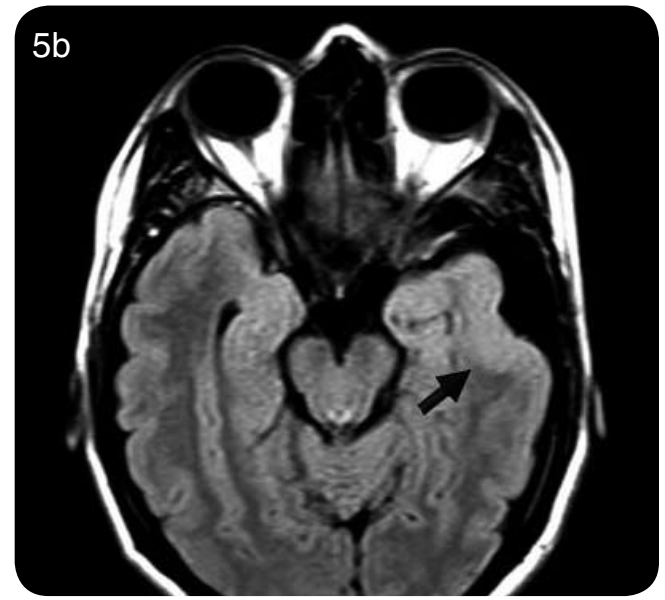

Figura 5. Engrosamiento cortical focal. Esquema (5a) con engrosamiento cortical focal frontal aislado y ausencia de otros signos radiológicos (flecha blanca). DCF temporal izquierda (5b) con engrosamiento cortical focal de la convexidad (flecha negra).

\section{b. Aumento de la señal de la corteza.}

El aumento de la intensidad de señal de la corteza cerebral se ha observado en los distintos tipos de DCF. Puede llegar a ser la única manifestación en los pacientes con displasia cortical leve (Figura 6).
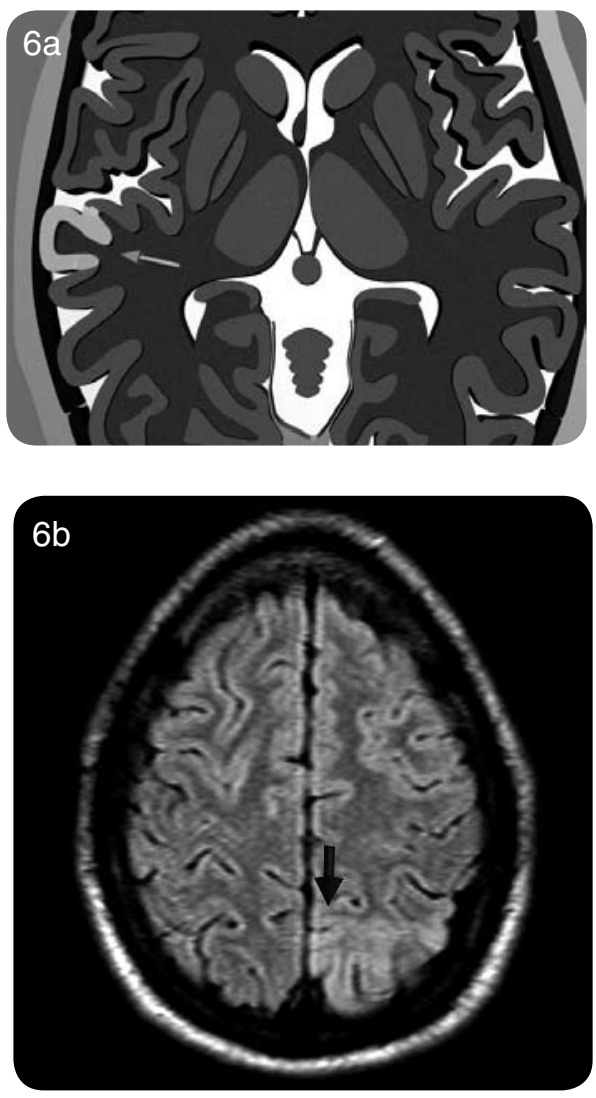

Figura 6. Aumento de la señal de la corteza. Esquema (6a) con hiperintensidad focal de la corteza (flecha blanca). DCF parietal izquierda (6b) con aumento de señal de la corteza cerebral y aumento de la señal de la SB subyacente (flecha negra). 
c. Borrosidad de la unión de la sustancia gris y sustancia blanca (SG-SB).

Se define como la pérdida de los límites entre la SG-SB, que también se ha descrito en todos los tipos de displasia cortical. Posiblemente corresponde al signo radiológico más difícil de identificar, especialmente debido a la presencia de artefactos por volumen parcial de los giros cerebrales. Esta alteración se produciría por la presencia de células anormales a nivel de la unión córtico-subcortical (Figura 7).
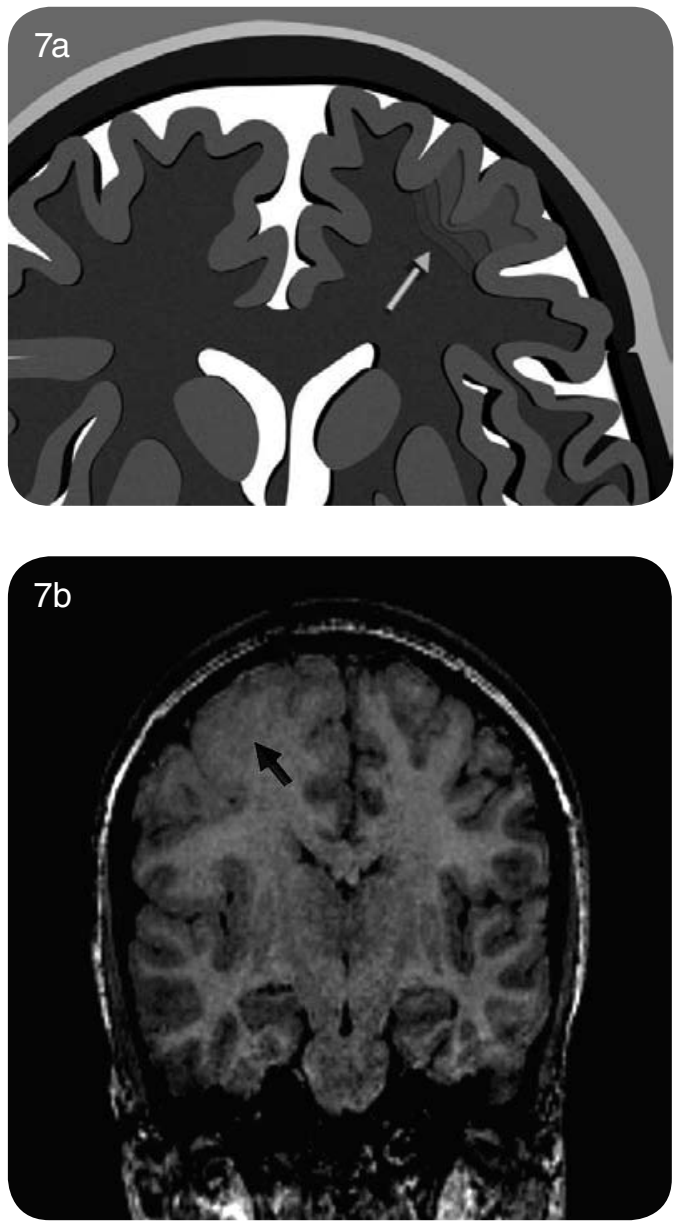

Figura 7. Borrosidad de la unión de la SG-SB. Esquema (7a) una menor definición focal del límite entre la SG y la SB (flecha blanca). Imagen potenciada en T1 de una DCF fronto-parietal derecha (7b) con borrosidad de unión entre la SG y SB (flecha negra).

\section{d. Hiperintensidad de la SB subcortical.}

Corresponde al aumento de la intensidad de señal subcortical curvilínea o radial visualizada en las imágenes ponderadas en T2 o FLAIR, frecuentemente con baja intensidad de señal en las imágenes ponderadas en T1. Se asocia a hipoplasia lobar focal en los casos de displasias corticales leves y en los casos de DCF tipo II se presenta junto al engrosamiento cortical y borrosidad de la SG-SB (Figura 8).

Hay que destacar que en los pacientes menores de 1 año la sustancia blanca subcortical normal es hiperintensa en las imágenes ponderadas en T2 por falta de mielinización, por lo que algunas DCFs pueden pasar desapercibidas (Figura 9). Debido a ésto, en los pacientes con alta sospecha debe realizarse un control a los 18 meses de vida.
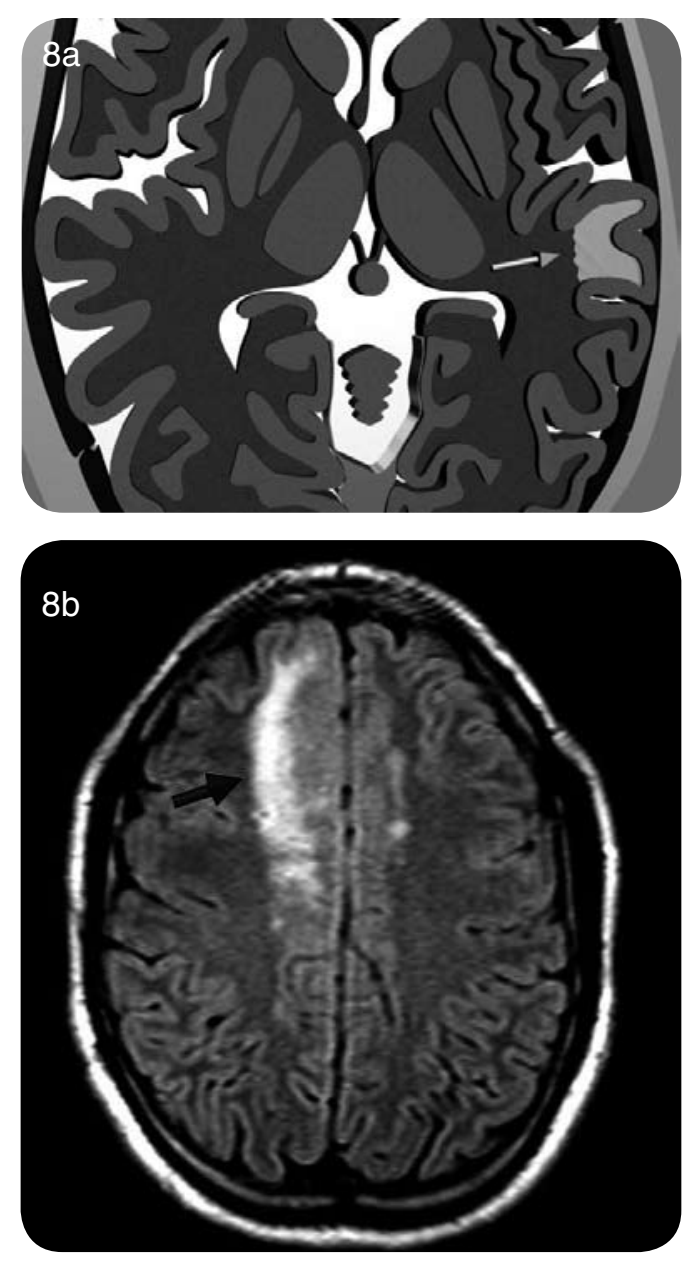

Figura 8. Hiperintensidad de la SB subcortical. Esquema (8a) con aumento de la intensidad de señal bajo la corteza (flecha blanca). DCF frontal derecha (8b) con hiperintensidad de la SB subcortical (flecha negra).

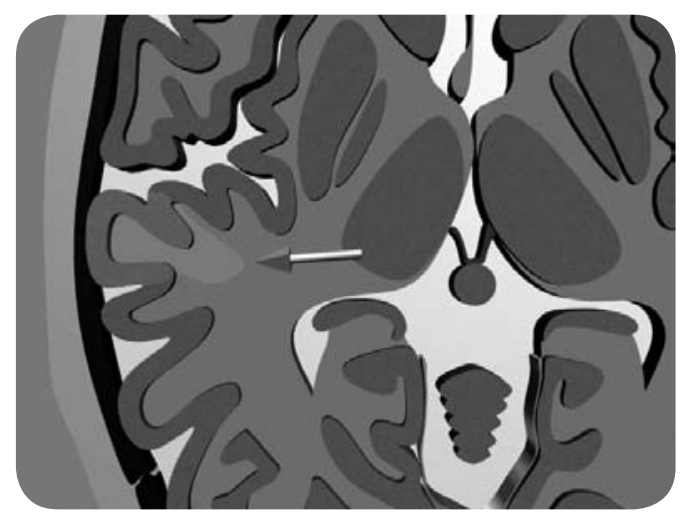

Figura 9. Hiperintensidad de la SB subcortical en menor de 1 año. Esquema con aumento de la intensidad de señal bajo la corteza (flecha blanca) que tiene prácticamente la misma intensidad de señal que el resto de la sustancia blanca, por lo que su diagnóstico es muy difícil. 
e. Lesión en embudo que se extiende desde la corteza hasta el ventrículo.

Lesión hiperintensa de la sustancia blanca que se extiende desde la unión córtico subcortical hasta la superficie ventricular con morfología de embudo con base hacia la corteza cerebral y vértice hacia el ventrículo (Figura 10).
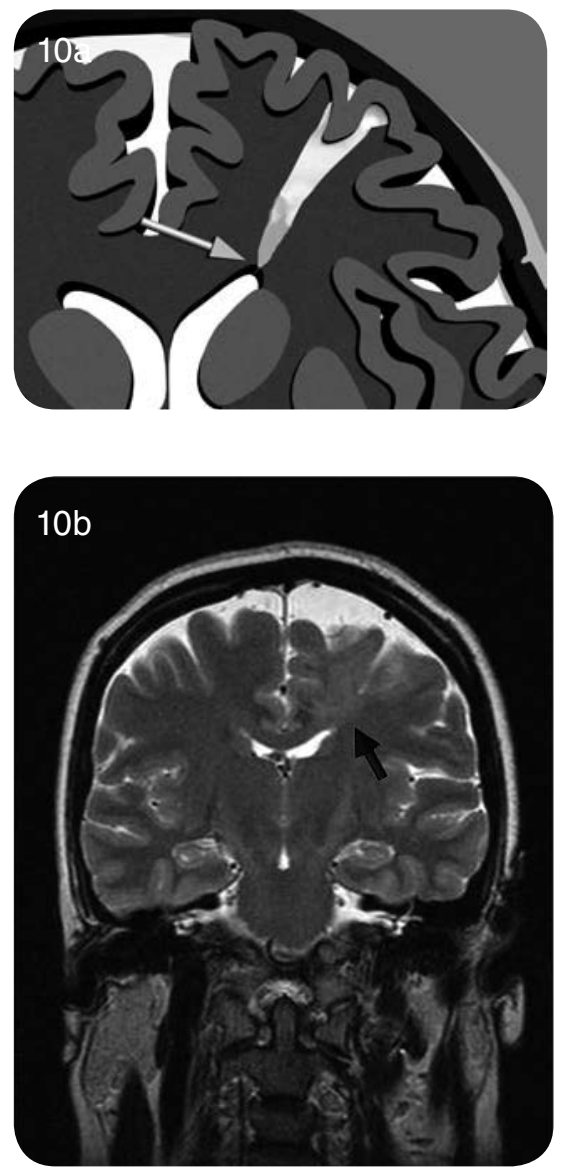

Figura 10. Lesión en embudo que se extiende desde la corteza hasta el ventrículo. Esquema (10a) con lesión de la SB que contacta el ventrículo (flecha blanca). DCF frontal izquierda (10b) con tenue lesión de la SB con base en la corteza y vértice en el cuerno frontal que comprueba se origen durante la fase de proliferación (flecha negra).

Este hallazgos ha sido descrito sólo en los pacientes con DCF tipo II y posiblemente traduce una alteración de la proliferación celular con migración y organización secundariamente alteradas ${ }^{(24)}$. Tassi demuestra esta alteración en el $20 \%$ de los pacientes con DCF tipo II, sin embargo hay que considerar que el $33 \%$ de estos pacientes no tuvieron alteraciones en la $\mathrm{RM}^{(23)}$.

\section{f. Alteración morfológica de la superficie cerebral.}

Corresponde a un patrón de giración alterado y surcos anormalmente ensanchados o profundos secundarios a la lesión subyacente (Figura 11)
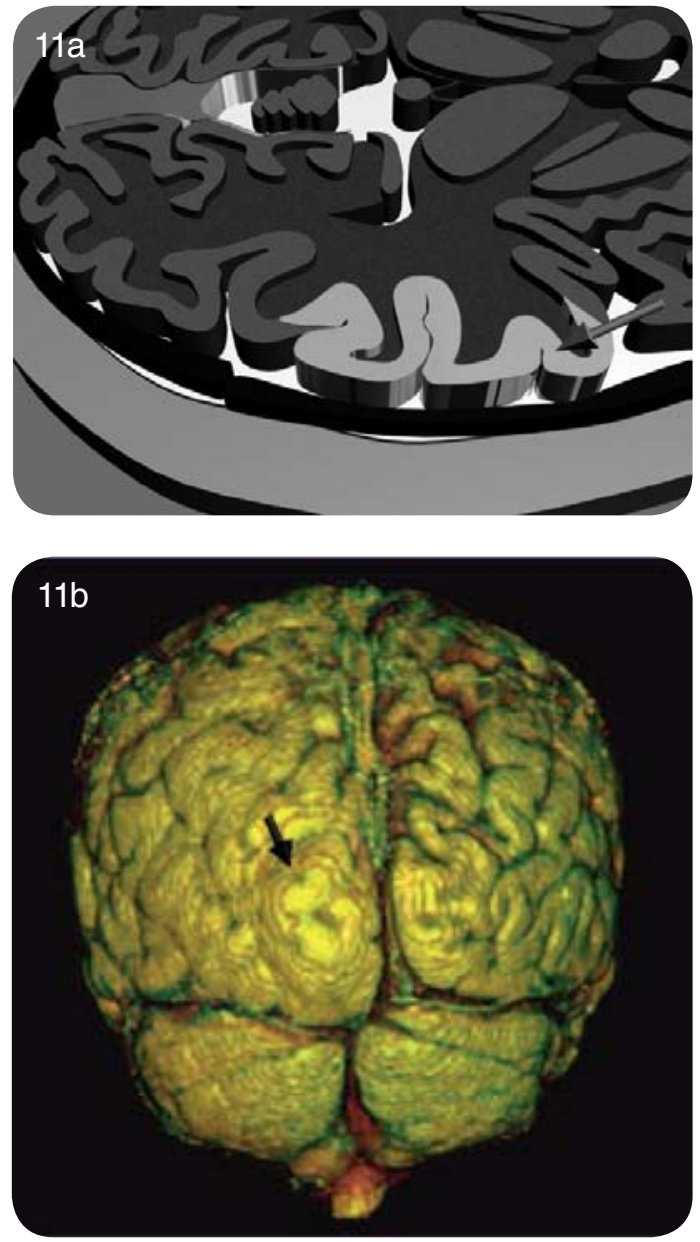

Figura 11. Alteración morfológica de la superficie cerebral. Esquema (11a) con ensanchamiento de los giros y disminución de la amplitud de los giros con corteza parietal derecha alterada se señal (flecha gris). DCF occipital izquierda (11b) con giros gruesos y surcos poco profundos (flecha negra). Gentileza Dr. Aaron Vidal.

\section{g. Hipoplasia lobar.}

Disminución de volumen de un lóbulo cerebral, generalmente temporal o frontal que ha sido descrita hasta en un $40 \%$ de los pacientes con displasias corticales leve, que se asocia a la presencia de un leve aumento de la intensidad de señal de la sustancia blanca subyacente ${ }^{(23)}$.

\section{LOCALIZACIÓN DE LAS LESIONES}

Las DCF se pueden localizar en cualquier parte de la corteza cerebral; sin embargo, las DCF tipo I se encuentran más frecuentemente en los lóbulos temporales y DCF II a nivel extratemporal.

\section{FISIOPATOLOGÍA}

La alteración de la señal de la displasia cortical se puede atribuir a hipomielinización de la SB, presencia de gliosis y presencia de células anormales. Sin embargo, la hiperintensidad de la SB subcortical se ha asociado más a la hipomielinización que a la 
presencia de células balonadas.

Es importante advertir que la extensión de la zona epileptógena puede ir más allá de la alteración estructural demostrada por la RM, especialmente en los pacientes con DCF tipo II, lo que ha sido corroborado con estudios electrocorticográficos ${ }^{(20)}$. Se estima que la zona epileptógena puede no relacionarse directamente con la malformación, pero puede estar a una corta distancia de ella.

\section{RECOMENDACIONES PARA PROTOCOLOS DE EPILEPSIA}

La mayoría de nuestros estudios de RM cerebral estándar son subóptimos para la identificación de un sustrato epileptógeno. Debido a ésto, se requiere de protocolos dirigidos con parámetros óptimos para el diagnóstico de este tipo de lesiones.

El enfrentamiento de un paciente con crisis focales debe ir dirigido a descartar las patologías más frecuentes asociadas, como la esclerosis mesial temporal (esclerosis hipocampal), displasias corticales, neoplasias, malformaciones vasculares y áreas de gliosis.

Los protocolos deben incluir imágenes volumétricas estructurales ponderadas en $\mathrm{T} 1$, generalmente en el plano sagital, en lo posible con voxeles isotrópicos de $1 \times 1 \times 1 \mathrm{~mm}$.

Para demostrar alteraciones de la señal se utilizan imágenes FLAIR, actualmente con los nuevos equipos es posible realizar incluso imágenes volumétricas de todo el cerebro.

Para el estudio del hipocampo se requiere de imágenes ponderadas en T2 de alta resolución coronales al eje del hipocampo. Debe incluirse además los polos temporales y las amígdalas.

Para el estudio de la diferenciación entre la sustancia gris y la sustancia blanca son útiles las imágenes de inversión-recuperación.

Se puede utilizar además imágenes STIR de alta resolución para demostrar las áreas más sutiles de la borrosidad del límite entre la corteza y la sustancia blanca.

El uso de contraste no está indicado en la evaluación de pacientes con epilepsia, sin embargo puede ser útil en los pacientes con epilepsia de inicio reciente para descartar alteraciones infecciosas, inflamatorias o neoplásicas, especialmente en pacientes mayores de 50 años ${ }^{(25)}$.

\section{RESONANCIA FUNCIONAL.}

La RM funcional es una técnica no invasiva que rutinariamente se utiliza en los casos de epilepsia refractaria, que ha contribuido al manejo y toma de decisiones quirúrgicas en los pacientes sometidos a una cirugía de epilepsia(26).

Actualmente cumple un rol primario en la evaluación pre-quirúrgica de las lesiones epilépticas intratables, ya que permite definir la relación anatómica entre las lesiones displásicas y las áereas funcionalmente elocuentes de la corteza cerebral para determinar el riesgo de déficit cuando son resecadas y permitir una máxima resección del tejido anormal con la menor morbilidad.

Las áreas funcionales más frecuentemente estudiadas corresponden a las áreas motoras (corteza precentral) y las áreas funcionales del lenguaje (áreas de Wernicke y Broca).

Esta técnica además provee información acerca de la posible reorganización de las áreas funcionales, lo que puede ser muy importante para determinar la estrategia quirúrgica.

Hay que considerar además que en algunos casos se ha demostrado cierto grado de funcionalidad alojada en el tejido displásico adyacente a las áreas elocuentes (Figura 12).
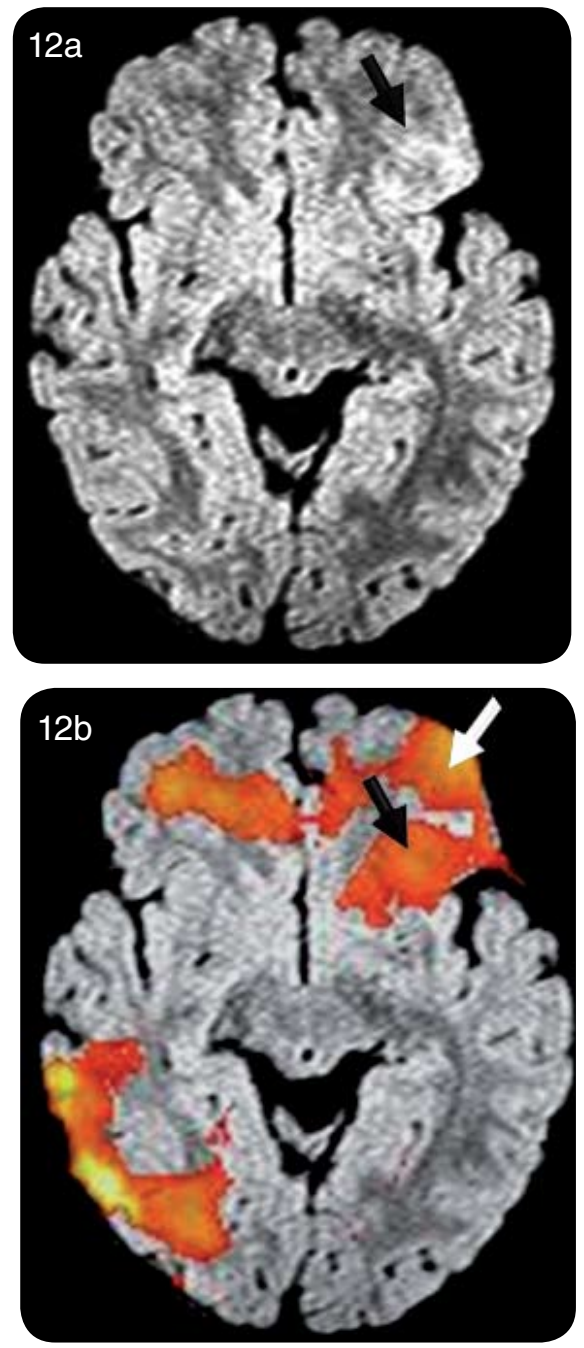

Figura 12. Paciente con DCF tipo II en el giro frontal inferior izquierdo. Imagen transversal FLAIR (12a) que muestra lesión hiperintensa en la mitad posterior del giro (flecha negra). RM funcional de expresión del leguaje sobrepuesta en la imagen FLAIR (12b) que muestra que la parte posterior del área de Broca se encuentra en la lesión (flecha negra) y su parte anterior se localiza en parénquima aparentemente normal (flecha blanca). 


\section{OTRAS TÉCNICAS}

En nuestro centro, actualmente utilizamos software de post-proceso que permite realizar la segmentación automática de las estructuras cerebrales con lo cual es posible determinar cuantitativamente el volumen de cada una de las estructuras, como por ejemplo el volumen hipocampal (Figura 13). Además se puede obtener gráficas 3D de la superficie cerebral y escalas en color que permiten visualizar el espesor cortical en cada región (Figura 14a). La insuflación de la malla de segmentación permite además visualizar el espesor cortical en la profundidad de los surcos (Figura 14b).

La espectroscopía ha demostrado utilidad en los pacientes con esclerosis temporal mesial en etapa inicial, en que pueden encontrarse alteraciones metabólicas previas a la aparición de la disminución del volumen o aumento de la señal. Además permitirían diferenciar las DCFs de lesiones tumorales ya que a pesar de las alteraciones de la estructura de la corteza se conservaría el pico de NAA (N-acetil aspartato), pudiendo existir un leve aumento de la colina y creatina.

La relaxometría corresponde a una técnica que permite hacer estudios cuantitativos de la intensidad de señal, que puede ser útil en las alteraciones muy precoces o alteraciones simétricas, que pueden ser difíciles de pesquisar.
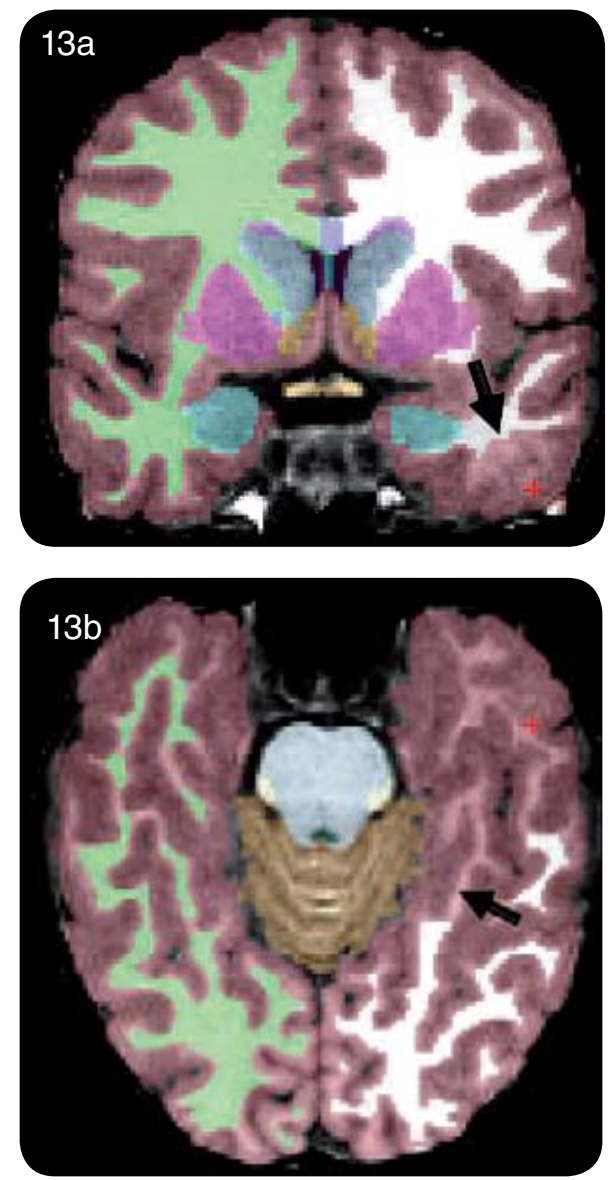
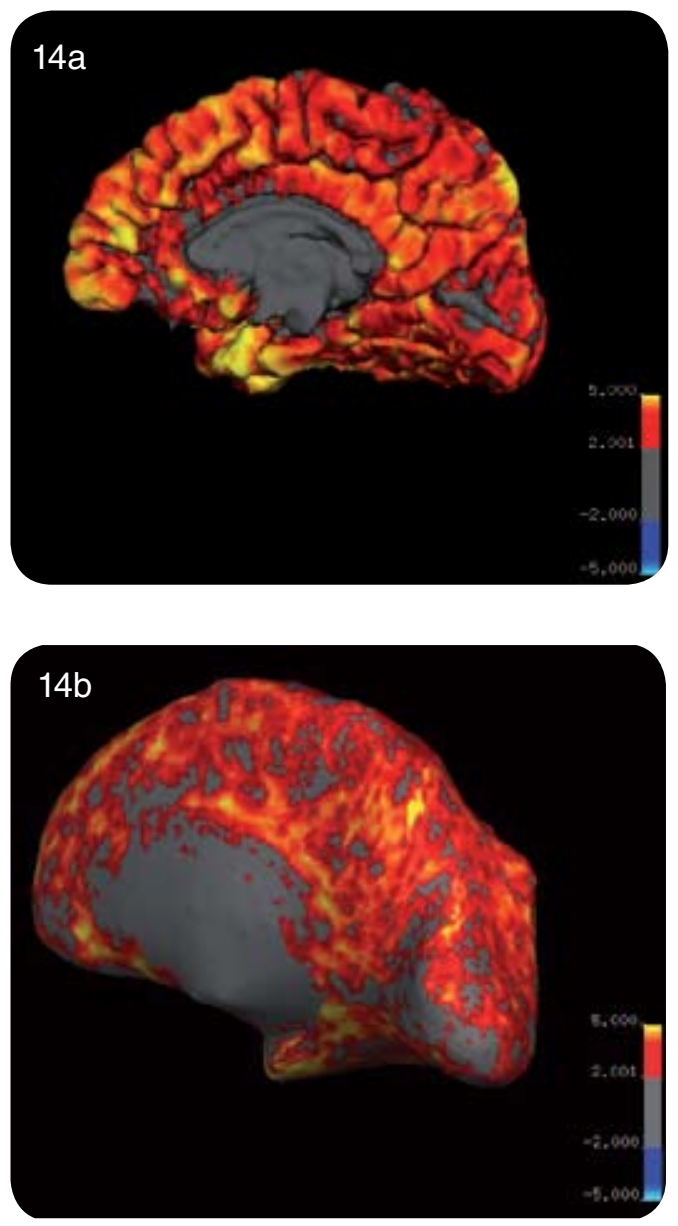

Figura 14. Imagen volumétrica T1 procesada con software Freesurfer (http://surfer.nmr.mgh.harvard.edu/) con reconstrucciones 3D que muestran el espesor cortical en milímetros. Imagen de la superficie medial del hemisferio cerebral derecho (14a) e imagen inflada (14b) del mismo hemisferio para visualizar el espesor cortical a nivel de los surcos. Nótese que es espesor cortical occipital medial es menor a $2 \mathrm{~mm}$ lo que es un hallazgo normal.

\section{PET CON FLUORDEOXIGLUCOSA}

Las células epileptógenas llegan a ser metabólicamente muy activas durante la crisis (período ictal); sin embargo esta área permanece menos activa que el tejido normal entre las crisis (período interictal) en la mayoría de los pacientes. Este defecto de captación de la glucosa se debería en parte a la presencia de gliosis (Figura 15).

Las imágenes PET con FDG (18 fluordeoxiglucosa) han mejorado la detección y localización de lesiones. 

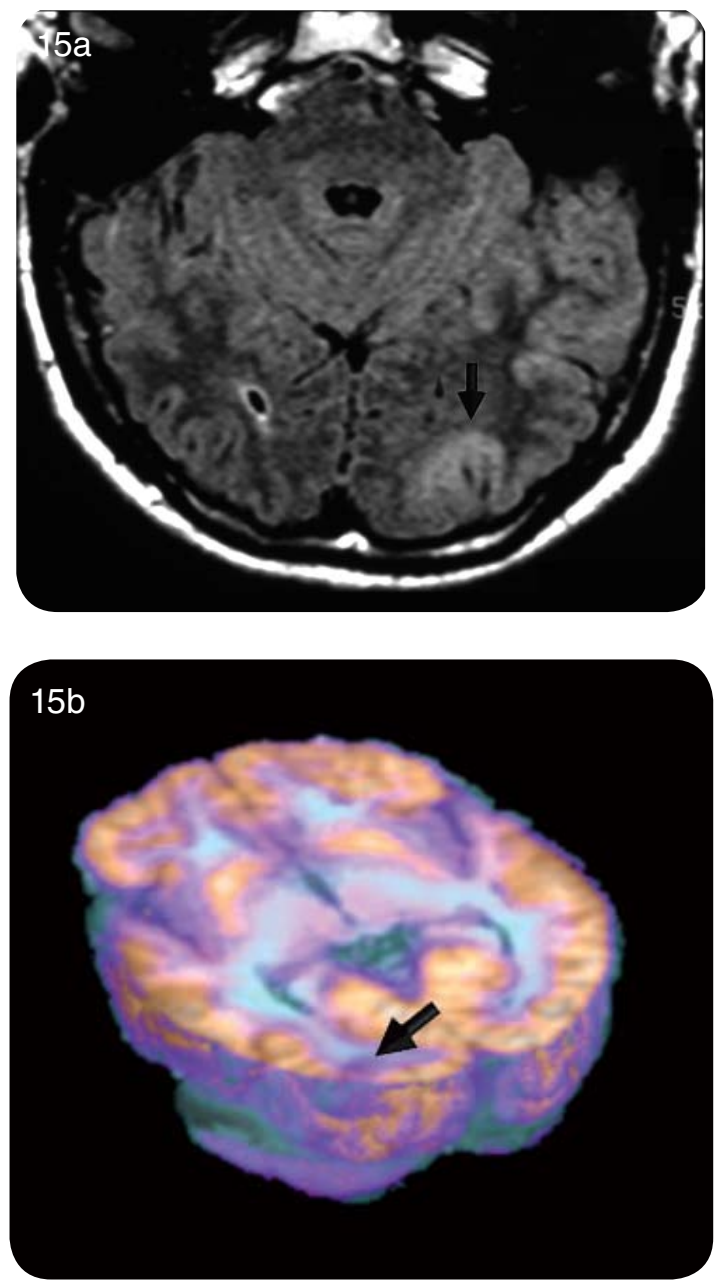

Figura 15. Paciente con DCF tipo II occipital izquierda. Imagen transversal FLAIR (15a) que muestra aumento de señal focal de la corteza y sustancia blanca subyacente (flecha negra). Fusión PET CT y RM (15b) que muestra foco hipometabólico coincidente con la lesión estructural (flecha negra).

\section{CO-REGISTRO PET Y RM}

Muchas alteraciones sutiles pueden pasar inadvertidas en las imágenes de RM, pero al contar con las zonas de hipometabólicas del PET y fusionarlas con las imágenes de RM hacen fácilmente identificable alteraciones sutiles ${ }^{(27)}$.

En algunas oportunidades es necesario normalizar el grado de captación de glucosa de las imágenes del paciente, comparándolas con un patrón normal según edad, para determinar alteraciones metabólicas sutiles o muy simétricas que son de difícil detección (Figura 16).

\section{ROL DE LAS IMÁGENES EN LA CIRUGÍA DE LAS DCFs:}

El objetivo de la cirugía de la epilepsia es conseguir la desaparición o disminución de las crisis en
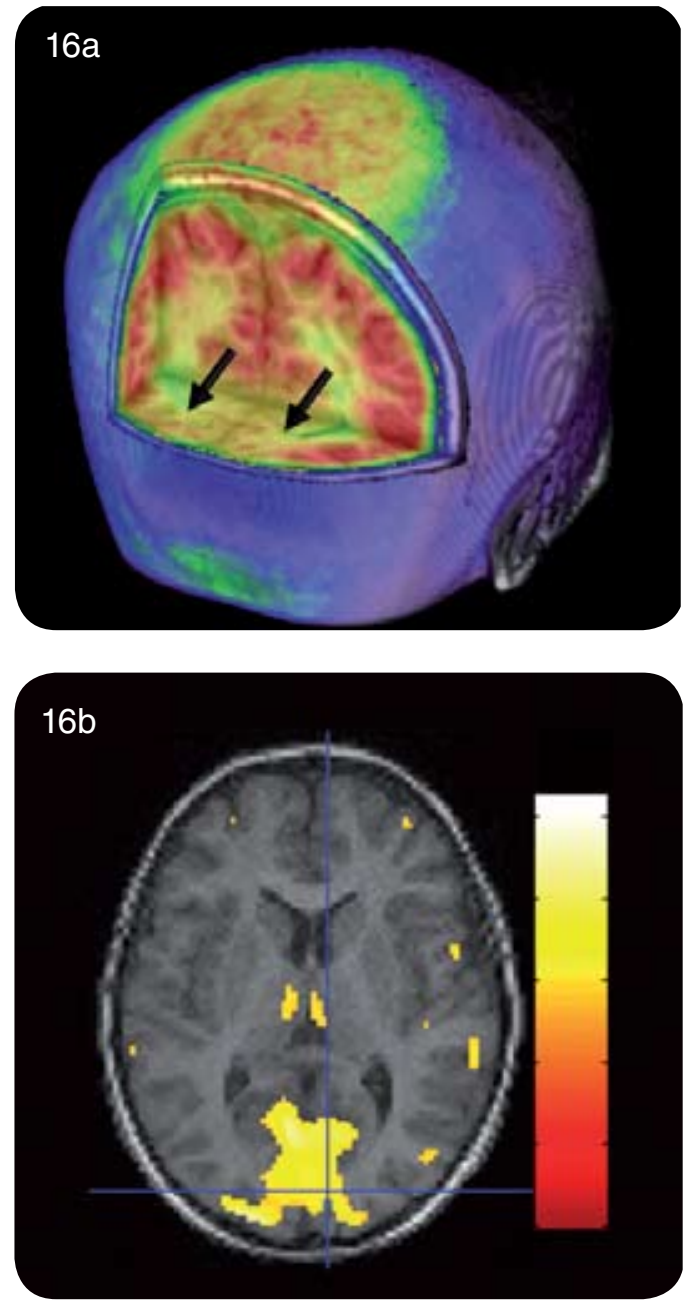

Figura 16. Paciente con crisis parciales. Fusión PET CT y RM (16a) que muestra hipometabolismo de ambos polos occipitales (flechas negras). Grado de captación de FDG comparándolo con una base de datos pacientes normales (Software FSL) que muestra focos con disminución del metabolismo de más de 2 DS en los polos occipitales (16b).

frecuencia e intensidad, por lo que es fundamental establecer su exacta localización mediante la semiología de las crisis, las alteraciones electroencefalográficas, el video monitoreo EEG e imágenes de RM y PET.

Se han descrito algunos factores pronósticos del éxito de la cirugía en relación al grado de visualización de la lesión, localización, número de lesiones, grado de resección, e histología. Los pacientes en que la lesión es visible en la RM tienen un mejor pronóstico post quirúrgico que los pacientes con RM normal(28).

La localización en el lóbulo temporal tendría un mejor pronóstico que las lesiones extratemporales. Algunos grupos han descrito que las displasias corticales leves tienen un mejor pronóstico, en gran parte sólo por su localización temporal ya que esta cirugía es relativamente más simple. 
Las lesiones multilobares tienen peor pronóstico que las lesiones unilobares.

El hecho de resecar completamente la lesión tiene un mejor factor pronóstico que la resección parcial. Debemos considerar que en algunos pacientes el tejido displásico se localiza parcialmente en un área elocuente y que la zona epileptógena puede extenderse más allá de la lesión identificada por la resonancia.

En relación al pronóstico de acuerdo a la histología se han reportado resultados disímiles. Algunos grupos han concluido que los pacientes con MLDC y DCF tipo I tienen mejor pronóstico post operatorio que las DCF tipo II ${ }^{(29)}$, posiblemente relacionado a su menor epileptogenicidad y su localización preferente en el lóbulo temporal. Otros grupos reportan que las DCF tipo II tendrían mejor pronóstico debido a que se encuentran mejor circunscritas en las imágenes de RM y por lo tanto es más fácil resecarlas en forma íntegra.

No es fácil sacar conclusiones claras de la evolución postquirúrgica de las MLDC, ya que su exacta definición es todavía un tema en discusión y debido a que no son fácilmente detectables mediante RM.

\section{EN RESUMEN}

Las neuroimágenes cumplen un rol fundamental en el diagnóstico de las displasias corticales, ya que son esenciales para demostrar la localización, morfología y extensión de estas alteraciones.

La clasificación histológica propuesta por Palmini pretende una mejor correlación entre las alteraciones de la RM y EEG, que permita una mejor delimitación del área epileptógena y eventualmente un mejor pronóstico postquirúrgico.

Aunque se han descrito los signos radiológicos de las displasias corticales, ellos no permiten diferenciar claramente entre los distintos tipos histológicos, principalmente debido a la sobreposición de los hallazgos.

Se han descrito factores pronósticos del éxito de la cirugía de la epilepsia en relación al grado de visualización de la lesión, localización, número de lesiones, grado de resección, e histología.

Las imágenes de RM funcional cumplen un rol fundamental en la evaluación quirúrgica de las lesiones epilépticas intratables, ya que permiten definir la relación anatómica del tejido displásico y las aéreas cerebrales elocuentes.

Las futuras mejoras de hardware y software junto con el post proceso de las imágenes nos ayudarán a entender la epileptogénesis de estas lesiones y ayudarán a los clínicos a entender su base estructural.

\section{BIBLIOGRAFÍA}

1. Devilat M. La Brecha en Epilepsia en Chile. Una dis- tancia entre lo deseable y lo posible. Revista Chilena de Epilepsia 2000, 1: 1-8.

2. Kwan $\mathrm{P}$, Brodie M. Early identification of refractory epilepsy. N Engl J Med 2000; 342: 314-9.

3. Bronen RA, Fulbright RK, Spencer DD, et al. Refractory epilepsy: comparison of MR imaging, CT, and histopathologic findings in 117 patients. Radiology 1996; 201:97-105.

4. Sisodiya SM. Surgery for malformations of cortical development causing epilepsy. Brain. 2000 Jun;123 (Pt 6): 1075-91.

5. Barkovich J, Kuzniecky RI, Dobyns WB, et al. A classification scheme for malformations of cortical development. Neuropediatrics 1996; 27: 59-63.

6. Barkovich AJ, Kuzniecky RI, Jackson GD, Guerrini R, Dobyns WB. A developmental and genetic classification for malformations of cortical development. Neurology 2005; 65: 1873-1887.

7. Sidman RL, Rakic P. Neuronal migration, with special reference to developing human brain: a review. Brain Res 1973; 62:1-35.

8. Blaser S, Jay V. Disorders of cortical formation: radiologic -pathologic correlation. Neuroimaging Clin N Am 1999; 9: 53-73.

9. Abdel Razek A, Kandell A, Elsorogy L, Elmongy A, Basett A. Disorders of Cortical Formation: MR Imaging. AJNR Am J Neuroradiol 2009; 30: 4 -11.

10. Taylor DC, Falconer MA, Bruton CJ, Corsellis JA. Focal dysplasia of the cerebral cortex in epilepsy. J Neurol Neurosurg Psychiatry 1971; 34: 369-387.

11. Cotter DR, Honavar M, Everall I. Focal cortical dysplasia: a neuropathological and developmental perspective. Epilepsy Res. 1999 Sep; 36(2-3):155-64.

12. Palmini A, Gambardella A, Andermann F, et al. Intrinsic epileptogenicity of human dysplastic cortex as suggested by corticography and surgical results. Ann Neurol 1995; 37: 476-87.

13. Semah F, Picot MC, Adam C, Broglin D, Arzimanoglou $A$, Bazin B, et al. Is the underlying cause of epilepsy a major prognostic factor for recurrence?. Neurology. 1998 Nov; 51(5):1256-62.

14. Kuzniecky R, Murro A, Kind D, Morawetz R, Smith J, Power R, et al. Magnetic resonance imaging in childhood intractable partial epilepsies: pathologic correlation. Neurology 1993; 43: 681-7.

15. Palmini A, Najm I, Avanzini G, et al. Terminology and classification of the cortical dysplasias. Neurology 2004; 62(Suppl 3): S2-S8. 16. Mischel PS, Nguyen LP, Vinters HV: Cerebral cortical dysplasia associated with pediatric epilepsy. Review of neuropathologic features and proposal for a grading system. J Neuropathol Exp Neurol 1995; 54: 137 -153. 17. Meencke HJ, Janz D. Neuropathological findings in primary generalized epilepsy: a study of eight cases. Epilepsia. 1984 Feb; 25(1):8-21.

18. Rojiani AM, Emery JA, Anderson KJ, Massey JK. Distribution of heterotopic neurons in normal hemispheric white matter: a morphometric analysis. J Neuropathol Exp Neurol. 1996 Feb; 55(2):178-83.

19. Bingaman WE: Surgery for focal cortical dysplasia. Neurology 2004; 62:S30-S34.

20. Boonyapisit K, Najm I, Klem G, Ying Z, Burrier C, LaPresto $E$, et al. Epileptogenicity of focal malformations due to abnormal cortical development. Direct 
electrocorticographic-histopathologic correlations. Epilepsia 2003; 44: 69-76.

21. Prayson RA, Estes ML. Cortical dysplasia: a histopathologic study of 52 cases of partial lobectomy in patients with epilepsy. Hum Pathol. 1995 May; 26(5):493-500

22. Colombo N, Tassi L, Galli C, Citterio A, Lo Russo G, et al. Focal Cortical Dysplasias: MR Imaging, Histopathologic, and Clinical Correlations in Surgically Treated Patients with Epilepsy. AJNR Am J Neuroradiol 2003; 24: 724-733

23. Tassi L, Colombo N, Garbelli R, Francione S, Lo Russo $G$, Mai R, et al. Focal cortical dysplasia: neuropathological subtypes, EEG, neuroimaging and surgical outcome. Brain 2002; 125: 1719-32.

24. Bronen RA, Vives KP, Kim JH, Fulbright RK, Spencer SS, Spencer DD. Focal cortical dysplasia of Taylor, balloon cell subtype: MR differentiation from lowgrade tumors. AJNR Am J Neuroradiol; 1997: 18(6): $1141-51$
25. Vattipally VR, Bronen RA. MR imaging of epilepsy: strategies for successful interpretation. Magn Reson Imaging Clin N Am. 2006 May; 14(2): 225-47.

26. De Tiège $X$, Connelly $A$, Liégeois $F$, Harkness W, Clark $\mathrm{CA}$, Chong WK, et al. Influence of motor functional magnetic resonance imaging on the surgical management of children and adolescents with symptomatic focal epilepsy. Neurosurgery. 2009 May; 64(5): 856-64.

27. Rastogi $\mathrm{S}$, Lee $\mathrm{C}$, Salamon N. Neuroimaging in pediatric epilepsy: a multimodality approach. Radiographics. 2008 Jul-Aug; 28(4):1079-95.

28. Kral T, Clusmann H, Blumcke I, et al. Outcome of epilepsy surgery in focal cortical dysplasia. J Neurol Neurosurg Psychiatry 2003; 74: 183-188.

29. Fauser S, Schulze-Bonhage A, Honegger J, Carmona H, Huppertz HJ, Pantazis G, et al. Focal cortical dysplasias: surgical outcome in 67 patients in relation to histological subtypes and dual pathology. Brain. 2004; 127: 2406-18. 